Türkiye Tarımsal Araştırmalar Dergisi
dergipark.gov.tr/tutad
Derk J Agric Res
2017, 4(2): 197-203
(TÜTAD
ISSN: 2148-2306
e-ISSN: 2528-858X
doi: 10.19159/tutad.294991

\title{
Nano Gübreler
}

\author{
Hatice DAĞHAN*
}

Eskişehir Osmangazi Üniversitesi, Ziraat Fakültesi, Toprak Bilimi ve Bitki Besleme Bölümü, Eskişehir, TÜRKIYE

\begin{abstract}
Geliş Tarihi/Received: 24.02 .2017
Kabul Tarihi/Accepted: 22.05 .2017

*Sorumlu Yazar/Corresponding Author: hdaghan@ogu.edu.tr

Özet: Her geçen gün erozyon, çevre kirliliği, bilinçsiz sulama ve gübreleme gibi nedenlerle tarım toprakları azalmaktadır. Diğer yandan artan nüfusun besin ihtiyaçlarmın yanı sıra gelişen gıda sanayinin ihtiyaçlarmı karşılamak için tarımsal üretimin arttırılması gerekmektedir. Son yıllarda, birim alan dan en yüksek miktarda ve kalitede üretim elde etmek için nano gübreler üretilmeye başlanmıştır. Yapılan araștırmalar, nanogübrelerin, bitki besin elementlerinin kullanım verimliliğinde bir artışa neden olduğunu, toprak toksisitesini azalttığını, fazla gübre kullanımının potansiyel olumsuz etkilerini en aza indirge di ğini ve gübre uygulama sıklığını azalttığını göstermektedir. Nano gübreler tarımda, ürün verimi ve besin maddesi kullanım etkinliğini artırmak, aşırı dozda kullanılan kimyasal gübrelerin kul lanımını azaltmak için önemlidir. Bu gübrelerin en önemli özellikleri makro ve mikro besin elementlerinden bir ya da birden fazlasını içermeleri, az miktarda ve sıkça uygulanabilmeleri ve çevre dostu olmalarıdır. Fakat yüksek dozda uygulandıklarında kimyasal gübreler gibi bitki büy ümesini ve ürün verimini azaltıcı etki gösterirler. Bu makalede, nano gübrelerin tanımlanması, önemi, sınıflandırılması, bitkisel üretiminde uygulaması, avantaj ve dezavantajları ve bu alanda elde edilen sonuçlar tartışılmıştır.
\end{abstract}

Anahtar Kelimeler: Nano teknoloji, toprak, makro nano gübre, mikro nano gübre

\section{Nano Fertilizers}

Abstract: Agricultural land is decreasing day by day due to erosion, environmental pollution, unconscious irrigation and fertilization. On the other hand, it is necessary to increase agricultural production in order to meet the needs of the developing industry as well as the nutritional needs of the growing population. In the recent years, nano fertilizers have begun to be produced to obtain the highest amount and quality of production from the unit area. Previous research shows that nano fertilizers cause an increase in the use efficiency of plant nutrients, reduce soil toxicity, minimize the potential adverse effects of excessive chemical fertilizer use, and reduce fertilizer application frequency. Nano fertilizers are important in agriculture to increase crop yield and nutrient use efficiency, and to reduce excessive use ofchemical fertilizers. The most important properties of these fertilizers are that they contain one or more of macro and micronutrients, they can be applied frequently in small amounts and are environmentally friendly. However, when applied at high doses, they exhibit decreasing effects on plant growth and crop yields, similar to chemical fertilizers. In this review, the definition, importan ce, and classification of nano fertilizers, their application in plant production, advantages and disadvantages and the results obtained in this field were discussed.

Keywords: Nanotechnology, soil, macro nano fertilizer, micro nano fertilizer

\section{Giriş}

Nüfus Referans Bürosu (PRB)'nun Ağustos 2016 yılı verilerine göre, bugünkü dünya nüfusunun (7.4 milyar) yaklaşık olarak \% 33 artışla 2050 yılında 9.9 milyara ulaşacağı tahmin edilmektedir (Anonymous, 2016). Nüfustaki bu artış beslenme, üretim ve enerjiye olan talep artışını da beraberinde getirecektir. $\mathrm{Bu}$ talepleri karşılayabilmek için tarımsal üretimin arttırılması gerekmektedir. $\mathrm{Bu}$ amaçla tarımsal üretimin en önemli kaynağı olan toprak; işleme, gübreleme, sulama ve toprak kökenli hastalıkları önleyici uygulamalar gibi tedbirlerle verimli hale 
getirilmeye çalışılmaktadır. Bitkiler tarafından kaldırılan besin elementlerinin toprağa ilavesi, bitkisel üretim ve ürün kalitesinin arttırılabilmesi için ise, gübreleme yapmak zorunlu hale gelmiştir (Sönmez ve ark., 2008).

Yirminci yüzyılda başlayan tarımda kimyasal gübre kullanımı günümüzde artış göstermiştir. Ancak, toprak analizi yapılmadan ihtiyaçtan fazla uygulanan kimyasal gübreler toprakta tuzlulaşma, ağır metal birikmesi, besin elementi dengesinin bozulmas1, mikroorganizma popülasyonu ve aktivitesinin zarar görmesi, sularda nitrat birikmesi ve ötrofikasyon oluşumu gibi olumsuz etkilere neden olmaktadır (Sönmez ve ark., 2008; Liu ve Lal, 2015).

Yanlış kimyasal gübre uygulanması ile toprakların $\mathrm{pH}$ dengesi bozulmakta ve asitlik oranı artarken; fosfor (P), kalsiyum (Ca) gibi bazı besin elementlerinin bitkiler tarafindan alınması engellen mekte, bitkilerde noksanlık ve gelişmede gerileme görülmektedir (Bellitürk, 2011). Diğer yandan, asit reaksiyonlu topraklarda pH'yı yükseltmek için uygulanan fazla miktarda kireç ve kireçli gübreler topraktaki besin elementi dengesini bozmakta; $\mathrm{P}$, bor (B), demir (Fe), çinko $(\mathrm{Zn})$ ve bakır $(\mathrm{Cu})$ gibi elementlerin fikse edilmesine neden olmaktadır. Bu olay bir yandan topraktaki besin elementi dengesinin bozulmasina sebep olurken, bir yandan da fikse edilen elementlerin noksanlığını gidermek üzere ilave gübreleme yapilmasina neden olmaktadır. Özellikle, fazla miktarda uygulanan fosforlu gübreler, toprakta mevcut olan $\mathrm{Ca}$ ile birlikte $\mathrm{Zn}$ ve demirin bitkiler tarafindan alınmasını engelleyerek besin elementi dengesini bozmaktadırlar (Bilen ve Sezen, 1993; Güneş ve ark., 2007).

Ürün verimini artırmak, çevre sorunlarını azaltmak, sürdürülebilir tarım ve çevre için yeni teknolojilerden yararlanarak yenilikçi, etkili gübrelerin geliştirilmesine ihtiyaç vardır. Nanoteknoloji birçok alanda yenilikçi fursatlar sunarken, özellikle gida ve tarımda nano materyallerin kullanımı artan nüfusun ihtiyaçlarını karş1lamak, birim alandan en az girdi ile en fazla ve en kaliteli ürün elde etmek aç isından son derece önemlidir. Cünkü ekilebilir tarım arazilerin in ve su kaynakların in sinırlı olması nedeniyle tarım sektörünün gelişmesi, modern teknolojilerin etkin bir şekilde kullanılarak eldeki kaynakların en az zararla kullanım etkinliğ inin artırılması ile mü mkündür. Modern teknolojiler a ras ında yer a lan nanoteknoloji; tarım sistemle ri, biyo medikal, çevre mühendisliğ $\mathrm{i}$, enerji dönüşümü ve diğer birçok alanda devrim potansiyeline sahiptir (Naderi ve
Danesh-Shahraki, 2013; Goel, 2015; Sing ve ark., 2017).

Yenilikçi bir bilim dalı olan nanoteknolojinin, gelecekte tarımsal üretim alan inda önemli bir role sahip olacağ 1 düşünülmektedir. Çünkü bu teknoloji ile üretilen nanogübrelerin kullanımı büyük bir hızla olmasa da her geçen gün artmaktadır. Bu derlemede, toprak ve su kaynaklarm 1 koruyarak bitkisel ürün verim ve kalitesini arttırmak için üretilen ve kullanılan nanogübreler, bu gübrelerin avantaj ve dezavantajları konusu ele alınmıştır.

\section{Nano Gübreler}

Nano, Yunanca bir sözcük olup son derece küçük, ufack gibi anlamlara gelmektedir. Bilimsel karşıllığ 1 ise, metrenin milyarda biri olan ölçü birimidir. Nanoteknoloji ise, boyutu $100 \mathrm{~nm}$ 'den küçük olan madde ve sistemleri inceleyen bir disiplin ve bilim dalıdır (Kayır ve Baççıl, 2010; Demirbilek, 2015; Liu ve Lal, 2016).

Nano gübreler; bitkiye bir ya da birden fazla besin elementi sağlayan ve bitkinin büyüme ve gelismesini arttıran nano malzemeler olarak tanımlanabilir (Liu ve Lal, 2016; Chhipa ve Joshi, 2016). Bu gübreler yavaş çözünen ve etkinliği yüks ek olan gübrelerd ir. Topraktan yıkan madan ya da değişime uğramadan, organik madde, kil ve kireç gibi maddelere bağlanmadan, diğer elementlerle bileşikler oluşturup yarayışsız forma geçmeden bitkiler tarafından kolayca alınan yavaş salınımlı nanogübreler daha çok tercih edilme potansiyeline sahiptir (Mukherjee ve ark., 2015).

Nano gübreler, geniş yüzey alanına sahip olmaların ın yanı sıra bitki kök ve yaprak gözenek boyutundan daha küçük boyutlara sahiptirler. $\mathrm{Bu}$ özellikleri nano gübrelerin uygulandıları yüzeyden bitkiye penetrasyonlarını ve besinlerin alımı ve kullanım etkinliği artabilir. Diğer yandan, parçacık boyutunun azaltılması ile nano gübrelerin birim alan başına spesifik yüzey alanın ın ve parçacık sayısının artırılmasını de sağlar. Böylece, nanaparçacıklar içinde kapsüllenmeş nanogübrelerin temas alanındaki artışla bitkiler uygulanan besin elementlerinden daha fazla yararlanabilecekleridir (Sing ve ark., 2017).

Nano gübre, bitki besin elementlerini şu üç yoldan biriyle bitkiye iletirler; 1) Besin elementi, nanotüpler veya nano gözenekli malzemeler gibi nanomalzemeler içine kapsüllenebilir, 11) ince bir koruyucu polimer film ile kaplanır veya 111) nano ölçekli boyutlardaki partiküller veya emülsiyonlar halinde bitkiye taşınırlar (Jampilek ve Kralova, 2015; Valizadeh ve Milic, 2016). 
Nano gübreler bitkinin sağlıklı büyüme ve gelișmesini sağlarlar. Böylece sağllklı olan bitki șiddetli ve değișken atmosferik koșullara ve hastalıklara karşı da daha fazla direnç kazanır. Ayrıca, tarımda kullanılan nano gübreler, bitkiye aktif maddelerin yapraktan püskürterek uygulanması ile toprakta aşırı kimyasal gübre uygulamasını azaltıp, optimum besin yönetimi sayesinde ürün miktarını arttırmaktadırlar (Mukherjee ve ark., 2015).

Toprakta yeterli miktarda alınabilir mikroelement içeriği bitkilerin patojenlere karş1 dayanıklılı̆̆ın 1 da artırmaktadır. Ancak bazı faktörler topraktaki besin elementlerinin bitkiler tarafından alımını sınırlamaktadır. Nötrden alkalin topraklara doğru besin elementlerinin toprak çözeltisinde bulunabilirliğ $\mathrm{i}$ ve bitki tarafından alınabilirliği azalmaktadır. Örneğin; toprak pH's1 alkaline yaklaştıkça topraklarda $\mathrm{Fe}$, mangan (Mn) ve $Z n$ biyoyarayışlılığ 1 azaldığ 1 için giderek kullanıla maz hale gelmekte ve kökler tarafından bu elementlerin alınmaları sinırlanmakta ve kökler enfeksiyona açık hale gelmektedir (Güneş ve ark., 2007; Serv in ve ark., 2015). Oysa makro ve mikro boyutların aksine, nano boyutlara getirilmiş gübreler bitkinin stoma açıklı̆̆ından rahatça geçebildiği için bitkinin minerallerden kolayca faydalanması sağlanırken, gübreden de \% 100'e yakın verim alınmaktadır. Nanoteknolojik gübre kullanımı sayesinde gübre israfinın önüne geçilerek ekimden maksimum verim alın maktadır. Buna ek olarak, çevresel ve ekonomik zararların da önüne geçilmiş olunur (Liu ve Lal, 2016).

Türkiye İstatistik Kurumu (TÜIK) verilerine göre, ülkemizde 2015 yılında toplam 10.777.779 ton kimyasal gübre tüketilmiştir (Anonim, 2017). Nanoteknolojik gübre sayesinde hem daha az gübre kullanmak, hem de ku llanılan az miktardaki gübreden en yüksek oranda verim almak mümkün olmaktadir.

Son dönemlerde, nano gözenekli zeolit, nano $\mathrm{Zn}$ gübresi, nano $\mathrm{B}$ gübresi, nano $\mathrm{Fe}$ gübresi, nano bakır $(\mathrm{Cu})$ gübresi vb. gübrelerin yanı sıra, bazı organik yapılı nano gübreler de üretilmeye başlanmıştır. Üretilen ve yoğun olarak kullanılan ve gelecekte daha da yoğun kullan 1 lması beklenen nano gübrelerin türü, içeriği, uygulama dozu, uygulama zaman1, uygulanan bitki çeșidi gibi pek çok faktöre bağlı olarak değ işecektir (Rameshaiah ve ark., 2015). Yukarıda değinilen tüm bu nedenlerden dolayı sürdürülebilir tarım için çevre dostu makro ve mikro besin elementleri ile desteklenmiş nano gübrelerin geliştirilmesi gerekmektedir.

\subsection{Makro ve mikro besin ele menti içeren nano gübreler}

Nano gübreler, makro ve mikro besin elementi nano gübreleri olarak sinıflandırılabilirler (Chhipa ve Joshi, 2016; Liu ve Lal, 2016). Makro nano element gübreleri bitkiler tarafında fazla miktarda ihtiyaç duyulan, bitkinin büyüme ve gelişmesi için mutlak gerekli olan azot $(\mathrm{N}), \mathrm{P}$, potasyum $(\mathrm{K})$, kükürt (S), $\mathrm{Ca}$ ve magnezyum $(\mathrm{Mg})$ gibi elementleri içeren nano gübrelerdir. Mikro element nano gübreleri ise bitkiler tarafından çok az miktarda ihtiyaç duyulan iz elementleri (Fe, Zn, $\mathrm{Cu}, \mathrm{Mn}, \mathrm{B}$ vd.) içeren gübrelerdir.

Birçok araștırmac1 yüksek verim sağlayan ve çevreyi koruyan nano gübreleri geliştirmek için çeşitli çalışmalar yapmaktadır.

Elfeky ve ark. (2013), randomize şansa bağlı blok deneme deseninde düzenlenen ve üç tekerrürden oluşan parsellere yaklaş $1 \mathrm{k} 15 \mathrm{~cm}$ boyundaki fesleğen (Ocimum basilicum L.) fideleri $30 \mathrm{~cm}$ aralıklarla ve her parselde 18 bitki olacak şekilde aktarmışlardır. Çiçeklenme dönemine kadar yetiştirilen fesleğen bitkisine topraktan ve yapraktan artan dozlarda $\left(1,2\right.$ ve $\left.3 \mathrm{mg} \mathrm{L}^{-1}\right) 12.6$ nm boyutunda $\mathrm{Fe}_{3} \mathrm{O}_{4}$ nanoparçacığ1 uygulanmıştır. Denemede yapraktan ve topraktan $\mathrm{Fe}_{3} \mathrm{O}_{4}$ nanaparçacık uygulamalarının fesleğen bitkisinin verim ve aktif uçucu yağ bileşenleri üzerine etkileri karşılaştırılmıştır. Sonuçlar fesleğen bitkilerine uygulanan $\mathrm{Fe}_{3} \mathrm{O}_{4}$ nanoparçacıklarının toplam klorofil, toplam karbonhidrat, uçucu yağ seviyeleri, Fe içeriği, bitki boyu, dal/bitki, yaprak/bitki, taze ağırlık ve kuru ağırlık miktarlarını önemli ölçüde arttırdığı ve yaprak sprey uygulamaların in toprak uygulamalarından daha etkili olduğu tespit edilmiştir.

Liu ve Lal (2014), sentetik apatit nano parçacıklarının soya fasulyesi (Glycine $\max$ L.) üzerindeki gübreleme etkisini değerlendirmek için bir sera denemesi yapmışlardır. Denemede 15.8 nm çaplı küre biçiminde ve kimyasal bileşimi saf hidroksiapatit $\left[\mathrm{Ca}_{5}\left(\mathrm{PO}_{4}\right)_{3} \mathrm{OH}\right]$ olan partiküller kullanılmıştır. Veriler, geleneksel $\mathrm{P}$ gübresi $\left[\mathrm{Ca}\left(\mathrm{H}_{2} \mathrm{PO}_{4}\right)_{2}\right]$ ile kıyaslandığında nano partiküller şeklinde uygulanan $\mathrm{P}$ gübresinin soya fasulyesinin büyüme oranını (\% 32.6) ve tohum verimini (\% 20.4) artırdığını göstermiştir. Biyokütle üretimi yeşil aksamda \% 18.2 ve kökte ise \% 41.2 oranında artış göstermiştir. Araştırmacılar yaptıkları çalışmaya göre apatit nano parçacıklarının yeni bir $\mathrm{P}$ gübre sınıfı olarak kullanmasının tarımsal verimliliğ $i$ arttırabileceğini ve ötrofikasyon riskini azaltılabileceğini bildirmişlerdir. 
Askari ve ark. (2014), kontrollü koșullarda Hogland besin ortamında (Fe-şelat içeren) yetiştirilen Catharanthus roseus bitkisine 70 gün boyunca altı farklı konsantrasyonda $(0,5,10,20$, 30 ve $40 \mu \mathrm{M})$ demir oksit $\left(\mathrm{Fe}_{3} \mathrm{O}_{4}\right)$ nanopartikülü uygulanmışlar ve elde ettikleri sonuçları kontrol bitkisiyle karşılaştırmalı olarak değerlendirmişlerdir. Deneme sonunda, $\mathrm{Fe}_{3} \mathrm{O}_{4}$ nanopartikül uygulamasin in yaprak büyüme parametrelerini ve karbonhidrat içeriğ ini belirgin bir şekilde arttırdığın 1, ancak $\mathrm{Fe}$ nanogübre uygulamasının bitkilerin prolin miktar1, antioksidanlar ve yaprağın stomal yoğunluğunda herhangi bir etki yapmadığı bildirilmişlerdir.

Delfani ve ark. (2014), börülce (Vigna unguiculata L.) bitkisine yapraktan $\mathrm{Fe}(0,0.25$ ve $0.5 \mathrm{~g} \mathrm{~L}^{-1}$, nano ve kimyasal formda $)$ ve $\operatorname{Mg}(0,0.5$ $g \mathrm{~L}^{-1}$ nano ve $0.5 \mathrm{~g} \mathrm{~L}^{-1}$ kimyasal formda) gübrelerini 3 tekerrürlü olarak, ekimden sonra 56 ve 72. günlerde uygulamışlardır. Analiz için bitki numuneleri 72. gün uygulamasindan 1 hafta sonra başlanarak her 2 haftada bir toplanmıştır. Analiz sonuçları Fe uygulamalarının verim, yaprak Fe içeriği, gövde $\mathrm{Mg}$ içeriği, plazma membran stabilitesi ve klorofil içeriği üzerine olumlu önemli bir etki yaptığını göstermiştir. En büyük etki ise iki uygulamanin kombinasyonu olan $0.5 \mathrm{~g} \quad \mathrm{~L}^{-1}$ kimyasal $\mathrm{Fe}+0.5 \mathrm{~g} \mathrm{~L}^{-1}$ nano-Mg ve $0.5 \mathrm{~g} \mathrm{~L}^{-1}$ kimyasal $\mathrm{Fe}+0.5 \mathrm{~g} \mathrm{~L}^{-1}$ kimyasal $\mathrm{Mg}$ uygulamalarından elde edilmiştir. Araştırıcılar bu iki elementin yapraktan uygulamalarının bitkinin fotosentetik verimliliğini artırdı̆ğnı ileri sürmüş lerdir.

Manjili ve ark. (2014), nano şelat molibden (Mo) gübresinin yapraktan uygulanmasının fistık verimi ve verim bileşenleri üzerindeki etkisini incelemek amaciyla, 2012 üretim sezonunda İran'ın Doğu Gilan bölgesinde bulunan Astaneh Ashrafieh şehrinde yürüttükleri tarla denemesini randomize blok deneme desenine göre 3 tekrarlamalı olarak düzenlemişlerdir. Bitki materyali olarak yerel fistık tohum çeşidi (NC2) kullanılmıştır. Azotlu gübrelerin (0-30-60 $\mathrm{kg} \mathrm{ha}^{-1}$ N) yarıs1 üre formunda ve taban gübresi olarak, diğer kalan kısmı ise yetiştirme periyodunun 20 , 30 ve 40 gün sonras inda uygulanırken, nano şelatlı Mo gübresinin $\left(0,1,2\right.$ ve $3 \mathrm{~g} \mathrm{~L}^{-1}$ nano-Mo) yarıs 1 dallanma döneminde ve geriye kalan 1 ise çiçeklenme döneminde yapraktan uygulanmıştır. Deneme sonunda elde edilen varyans analizinin sonuçları, nano șelat Mo uygulamasının bitki boyu, bitki başına kapsül sayısı, bitki başına olgun kapsül sayısı, yüz tohum ağ ırlığı, bitki başına tohum sayıs1, tohum uzunluğu, tohum ve kapsül verimi, yanal dal sayısı ve biyolojik performans gibi özellikler üzerine önemli bir etkiye sahip olduğunu göstermiştir. Ayrıca, nano şelat Mo gübresinin farklı değerlerine ait ortalamalar karşılaştırıldığ 1 da, en yüksek kapsül ve tohum veriminin (2320 ve $3715 \mathrm{~kg} \mathrm{ha}^{-1}$ s rrasiyla) $3 \mathrm{~g} \mathrm{~L}^{-1}$ nano-Mo gübre uygulamasından elde edildiğini göstermiştir.

Benzon ve ark. (2015), nano gübre $(\mathrm{N}>\%$ 1.2; $\left.\mathrm{P}_{2} \mathrm{O}_{5}>\% 0.001 ; \mathrm{K}_{2} \mathrm{O}>\% 0.0001\right)$ ve geleneksel kimyasal gübre $\left(11 \mathrm{~kg} \mathrm{~N}, 7 \mathrm{~kg} \mathrm{P}_{2} \mathrm{O}_{5}\right.$ ve $\left.8 \mathrm{~kg} \mathrm{~K} \mathrm{~K}_{2} \mathrm{O}\right)$ uygulamaların in pirinç bitkisinin verimliliğ $i$, toplam fenol içeriğ i (TPC) ve antioksidan aktivitesi üzerine etkilerini serada saksı (15 kg) denemesiyle karşılaştırmış lardır. A raştırıcılar nano gübre uygulamasin in pirinçte büyüme, gelişme, toplam fenol içeriği ve antioksidan aktivitesini desteklediğini ve bitki üretimini geliştirme potansiyelinin olduğunu bildirmişlerdir.

Rostami Ajirloo ve ark. (2015), 2013-2014 büyüme sezonunda yürüttükleri tarla denemesinde artan dozlarda $\left(0,100,200,300\right.$ ve $\left.400 \mathrm{~kg} \mathrm{ha}^{-1}\right)$ nano $\mathrm{K}$ ve saf azot $\left(0,50,100,150\right.$ ve $\left.200 \mathrm{~kg} \mathrm{ha}^{-1}\right)$ gübre uygulamalarının domates (Lycopersicone sculentum L.) bitkisinin verim ve verim unsurları üzerine etkilerini araştırmışlardır. Araştırma sonucunda en yüksek bitki boyu ve kök çapına 400 $\mathrm{kg} \mathrm{K} \mathrm{ha}{ }^{-1}$ nano gübre uygulamasından, bitki başına en fazla meyve, meyve ağırlı̆̆ı, meyve çapı ve meyve verimi oranına ise, $300 \mathrm{~kg} \mathrm{~K} \mathrm{ha}^{-1}$ nano gübre uygulamasından elde edilmiştir. Diğer yandan $\mathrm{N}$ gübre uygulanmasi ise, domates verimini ve verim unsurlarını arttırmıștır. Araştırmacılar nano $\mathrm{K}$ gübresinin ve $\mathrm{N}$ 'lu gübre uygulanmalarının domates verimini ve verim bileşenlerini artırd $\breve{g ̆}_{1}$ bildirmişlerdir. Bu çalış mada nano $\mathrm{K}$ gübresi ve $\mathrm{N}$ gübresinin kombine uygulamasının, bu gübrelerin tek başına uygulamalardan daha iyi bir etkiye sahip olduğu, ayrica nano $\mathrm{K}$ gübresinin ve $\mathrm{N}$ gübresinin domatesin büyüme ve meyve verimi üzerinde sinerjik bir etkiye sahip olduğu sonucuna varılmıştır.

Hassani ve ark. (2015), kimyasal gübreler (Fe, $\mathrm{Zn}$ ve $\mathrm{K}$ ) ve nano ( $\mathrm{Fe}, \mathrm{Zn}$ ve $\mathrm{K}$ ) gübrelerin ayr1 ayrı ve kombinasyonlarını uygulandıkları nane (Mentha piperita L.) bitkisinin boyu, gövde, dal ve yaprak sayıs1, bitkin in (gövde, dal, yaprak) yaş ve kuru ağırlığ1, ve verim üzerine etkilerini araștırmışlardır. Deneme İran' in Khuzestan bölgesinin Sardasht kentinde tarla denemesi olarak yürütülmüştür. Sonuçlar kimyasal ve nano gübrelerin bitki boyu, dal sayısı, yaprak ve gövde yaş ağırlı̆̆ $\ln 1$ istatiksel olarak \% 1 oranında etkilerken bitki yaş ağırlığ $1 \mathrm{n} 1 \% \quad 5$ düzeyinde etkilediğini göstermiştir. En yüksek bitki boyu $(11.67 \mathrm{~cm})$, dal sayıs1 (58.2), daldaki yaprak sayıs1 (916.3), boğum sayısı (16.6), yaprak yaş ağırlı̆̆1 (219), yaprak kuru ağırlığı (26.7 g), gövde yaş 
ağırlığ 1 (66.42 g), gövde kuru ağırlığ1 (23.1), bitki yaş (140.8 g) ve kuru (40.34 g) ağ rrlıkları nano gübre uygulamalarından elde edilmiştir. Araştırmacilar elde ettikleri sonuçlara göre kimyasal gübre uygulamasının negatif bir etkisi olmamasına rağmen nano gübre uygulamalarının bitkisel verim üzerinde daha etkili olduğu bildirmişler ve nano gübre kullanımını önermişlerdir.

Davarpanah ve ark. (2016), $\mathrm{Zn}$ ve B nano gübrelerinin yapraktan uygulamasının nar bitkis in in meyve verimi ve kalitesi üzerine etkisini araştırmışlardır. Çalışmada; tam çiçeklenme öncesinde yapraklara nano-Zn şelat 0,60 ve 120 $\mathrm{mg} \mathrm{L}^{-1}$ dozlarında ve nano-B şelat gübresi ise 0 , 3.25 ve $6.5 \mathrm{mg} \mathrm{L}^{-1}$ dozlarında ağaç başına $5.3 \mathrm{~L}$ oranında uygulanmıştır. Çinko ve B uygulaması ile yapraklarda her iki mikro elementin konsantrasyonu artmıştır. Nispeten düşük miktarda $B$ veya $Z n$ nano-gübresi (sırasıyla $34 \mathrm{mg} \mathrm{B/ağaç}$ veya $636 \mathrm{mg} \mathrm{Zn} /$ ağaç) içeren tek bir yaprak spreyi uygulaması ağaç başına meyve sayısındaki artışa bağlı olarak narın meyve veriminde artışına neden olmuştur.

Ghiyasi ve ark. (2016), kuraklık koşullarında nano besin maddeleri priminginin tritikale (Triticosecale wittmack) tohumunun biyolojik özelliklerine etkisini araştırdıkları bir çalışmada, tritikaleye artan 5 farklı kuraklık düzey inde $(0$, $0.25,-0.5,-0.75$ ve $\left.-1 \mathrm{M}_{\mathrm{pa}}\right)$ ve priming ikinci faktör olarak 3 düzeyde (\% 1 nano-Zn, $\% 1$ nano titaniyum ve kontrol) uygulamışlardır. Araştırmada, yapılan uygulamaların tritikale bitkis in in çimlenme oran1, çimlenme h1zı, kökçük ve sapcık uzunluğu gibi çimlenme indekslerine etkileri belirlenmiştir. Elde edilen veriler, çimlenme oranı ve diğer özelliklerin kuraklık ve primingden etkilendiğ ini ancak istatistiksel bakımdan anlamlı farklılık göstermedikleri, kuraklıkta nano çinko ile primingin çimlenme oranı ve fide büyümesini geliştirdiğ ini göstermiştir. Ayrıca çimlenme hızının gelişmesinde nano titanium priminginin en etkili uygulama olduğu bildirilmiştir.

Yapılan tüm bu çalışmalar nanoteknolojinin, özellikle gelişmekte olan ülkelerde gelecek vaat eden ve yüksek kullanım potansiyele sahip bir teknoloji olduğunu ve üretilen nano gübrelerin ise tarımsal üretim açısından önemli bir ürün olduğunu göstermektedir.

\subsection{Nano gübrelerin avantajları}

Nano gübreler sahip oldukları ultra küçük boyutlar sayesinde stomalardan kolaylıkla geçerek bitkin in minerallerden kolayca faydalanmasina olanak sağla maktadırlar (Liu ve Lal, 2016; Sing ve ark., 2017). Böylece uygulanan gübreden en yüksek verim alınabileceği bild irilmiştir. Bunun yanı sıra geleneksel gübrelerle karşılaştırıldığ inda, nano gübrelerin bir çok avantajaları vard ır (Liu ve Lal, 2015; Rameshaiah ve ark., 2015; Solanki ve ark., 2015; Sing ve ark., 2017). Bu avantajlar şöyle siralanabilir;

a. Az miktarda gübre tüketilerek düşük maliyetle yüksek oranda verim alınabilmesi,

b. Gübre kullanım etkinliğini arttırmas1,

c. Besin kullanım verimliliğini arttırması,

d. Gübre uygulama sıklığını azaltması,

e. Besin kay ıplarını azaltması ve çevre üzerine olas1 olumsuz etkileri en aza indirmesi,

f. Toprak toksisitesini azaltmas 1,

g. Toprak verimliliğ $i$ ve ürün kalitesini artırmas1,

h. Nanogübreler bitkinin sağlıklı büyüme ve gelişmesini sağlayarak ürün verimini, besin değerini arttırırlar. Böylece sağlıklı olan bitkinin hastalıklara ve şiddetli hava koşullarına karşı daha fazla direnç kazanmasıda nano gübrelerin önemli bir avantajıdır.

\subsection{Nano gübrelerin dezavantajları}

Birçok üstün özelliklerine rağmen nano gübrelerin bazı olumsuz etkileri de bulun maktadır. Alımlı bir terim olan nanoteknolojide kullanılan nano boyuttaki partiküller sağlığa ve aynı zamanda çevreye karşı bazı önemli riskler ve sorunlara neden olabilmektedir. Nano malzemelerle ilgili gerçekleştirilen ilk çalışmalar, nano partiküllerin insan sağllğ 1 üzerine ciddi tehlikelere ve toksik etkilere neden olduğunu göstermiştir. Bu nedenle, nano gübrelerin olası en önemli olumsuz etkisi içerdikleri nano partiküllerin sağlık açısından tehlikeli olabilmeleridir. Nano partiküller insan vücuduna girdikleri zaman tüm hayati organlara ulaşarak dokularda zararlara neden olabilmektedirler. Yapılan bazı çalışmalar da bu gübrelerin toksik etkilere de sahip olduklar1, ekosistem için ciddi bir tehdit unsuru oldukları ve yarattıkları çevre sorunlarının onarımın ın oldukça güç olduğu bildirilmiştir (Rameshaiah ve ark.,2015; Solanki ve ark., 2015).

\section{Sonuç ve Öneriler}

Nanoteknolojin in tıp, sanayi, tarım gibi oldukça geniş bir uygulama ve kullanım alanı vardır. Özellikle tarımsal alanda artan nüfusun besin ihtiyacının karşılanması, ürün verim ve kalitesinin arttırılmas1, kimyasal gübre miktar1 ve maliyetinin azalması açısından geliştirilen nano gübreler bu teknolojin in en önemli ürünlerinden birid ir. Ultraküçük boyutlar nano partikülleri muazzam yararlı yapmakta, ne yazık ki aynı özellik birçok yan 
etkilere de neden olmaktadır. Yaşam kalitesinin arttırılması için birçok alanda kullanılan nanoteknolojik ürünlerin avantajlarının yanında olas 1 çevre ve insan sağ lı̆̆ üzerine olası risklerinin dikkate alınması gerekmektedir. Toprak-bitki sisteminde nano gübrelerin avantaj ve dezavantajları dikkate alınarak birim alandan en yüksek verim elde edilmesin in yanında çevresel etkileri de dikkate alınarak bu gübrelerin kullanımlarında bilinçli davranılması gerekmektedir.

\section{Kaynaklar}

Anonim, 2017. Bitkisel Üretim İstatistikleri, Tarımsal Gübre İstatistikleri. Türkiye İstatistik Kurumu, http: //www.tuik.gov.tr/PreTablo.do?alt_id=1001 (Erişim tarihi: 20.05.2017).

Anonymous, 2016. World Population Data Sheet (WPDS) 2016. http://www.prb.org/Publications/ Datasheets/2016/2016-world-population-data-sheet. asp x (Erişim tarihi: 10.02.2017).

Askari, M., Amirjani, M.R., Saberi, T., 2014. Evaluation of the effects of iron nanofertilizer on leaf growth, antioxidants and carbohydrate contents of catharanthus roseus. Journal of Plant Process and Function, 3(7): 43-55.

Bellitürk, K., 2011. Tarım topraklarının kullanımında ve gübrelenmesinde yapılmas1 ve yapilmamas1 gerekenler üzerine bir değerlendirme. Gübretaş'la Verim Periyodik Kurumsal Bülten, 7(25): 24-26.

Benzon, H.R.L., Rubenecia, M.R.U., Ultra, Jr.V.U., Lee, S.C., 2015. Nano-fertilizer affects the growth, development, and chemical properties of rice. International Journal of Agronomy and Agricultural Research, 7(1): 105-117.

Bilen, S., Sezen, Y., 1993. Toprak reaksiyonunun bitki besin elementleri elv erişliliği üzerine etkisi. Atatürk Üniversitesi, Ziraat Fakültesi Dergisi, 24(2): 156166.

Chhipa, H., Joshi, P., 2016. Nanofertilisers, Nanopesticides and Nanosensors in Agriculture. Chapter 9. In: S. Ranjan, N. Dasgupta and E. Lichtfouse (Eds.), Nanoscience in Food and Agriculture 1, Volume 20 of the series Sustainable Agriculture Reviews, Springer International Publishing Switzerland, pp. 247-282.

Davarpanah, S., Tehranifar, A., Davarynejad, G., Abadía, J., Khorasani, R., 2016. Effects of foliar applications of zinc and boron nano-fertilizers onpomegranate (Punica granatum cv. Ardestani) fruit yield and quality. Scientia Horticulturae, 210: 57-64.

Delfani, M., Baradarn, F.M., Farrokhi, N., Makarian, H., 2014. Some physiological responses of black-eyed pea to iron and magnesium nanofertilizers. Communications in Soil Science and Plant Analysis, 45(4): 530-540.

Demirbilek, M.E., 2015. Tarımda ve gidada nanoteknoloji. Gida ve Yem Bilimi-Teknolojisi
Dergisi / Journal of Food and Feed ScienceTechnology, 15: 46-53.

Elfeky, S.A., Mohammed, M.A., Khater, M.S., Osman, Y.A.H., Elsherbini, E., 2013. Effect of magnetite nano-fertilizer on growth and yield of Ocimum basilicum L. International Journal of Indigenous Medicinal Plants, 46(3): 1286-1293.

Ghiyasi, M., Amirnia, R., Bayat, M., 2016. Kuraklık koşullarında nano besin maddeleri priminginin tritikale (Triticosecale wittmack) tohumunun biyolojik özelliklerine etkisi. Tarım Bilimleri Araştırma Dergisi, 9(2): 42-44.

Goel, A., 2015. Agricultural applications of nanotechnology. Journal of Biological and Chemical Research, 32(1): 260-266.

Güneş, A., Alpaslan, M., İnal, A., 2007. Bitki Besleme ve Gübreleme. Ankara Üniversitesi, Ziraat Fakültesi Ders Kitab1, No: 504, Yayın No: 1551, Ankara Üniversitesi Basımevi, Ankara.

Hassani, A., Tajali, A.A., Mazinani, S.M.H., 2015 Studying the conventional chemical fertilizers and nano-fertilizer of ron, zinc and potassium on quantitative yield of the medicinal plant of peppermint (Mentha piperita L.) in Khuzestan. International Journal of Agriculture Innovations and Research, 3(4): 1078-1082.

Jampilek, J., Kralova, K., 2015. Application of nanotechnology in agriculture and food industry, its prospects and risks. Ecological Chemistry and Engineering S, 22(3): 321-361.

Kayır, Y.Z., Baççıl, E.G., 2010. Nanoteknoloji nedir? http://www.metalurjist.gen.tr/docs/makale4.pdf (Erişim tarihi: 15.06.2014).

Liu, R., Lal, R., 2014. Synthetic apatite nanoparticles as a phosphorus fertilizer for soybean (Glycine max). Scientific Reports, 4: 1-6.

Liu, R., Lal, R., 2015. Potentials of engineered nanoparticles as fertilizers for increasing agronomic productions. Science of the Total Environment, 514: 131-139.

Liu, R., Lal, R., 2016. Nanofertilizers. In: R. Lal (Ed.) Encyclopedia of Soil Science, 3rd Edition, CRC Press, p: 1511-1515.

Manjili, M.J., Bidarigh, S., Amiri, E., 2014. Study the effect of foliar application of nano chelate molybdenum fertilizer on the yield and yield components of peanut. Biological Forum-An International Journal, 6(2): 37-40.

Mukherjee, A., Sinha, I., Das, R., 2015. Application of nanotechnologv in agriculture: Future prospects. Outstanding Young Chemical Engineers (OYCE) Conference, March 13-14, DJ Sanghvi College of Engineering, Mumbai, India.

Naderi, M.R., Danesh-Shahraki, A., 2013. Nanofertilizers and their roles in sustainable agriculture. International Journal of Agriculture and Crop Sciences, 5(19): 2229-2232.

Rameshaiah, Dr.G.N., Pallavi, J., Shabnam, S., 2015. Nano fertilizers and nano sensors: An attempt for developing smart agriculture. International Journal 
of Engineering Research and General Science, 3(1): 314-320.

Rostami Ajirloo, A., Shaaban, M., Motlagh, Z.R., 2015. Effect of $\mathrm{K}$ nano-fertilizer and $\mathrm{N}$ bio-fertilizer on yield and yield components of tomato (Lycopersicon esculentum L.). International Journal of Advanced Biological and Biomedical Research, 3(1): 138-143.

Servin, A., Elmer, W., Mukherjee, A., De La TorreRoche, R., Hamdi, H., White, J.C., Bindraban, P. Dimkpa, C., 2015. A review of the use of en gin eered nanomaterials to suppress plant disease and enhance crop yield. Journal of Nanoparticle Research, 17: 92-113.

Singh, M.D., Chirag, G., Prakash, P.O., Mohan, M.H., Prakasha, G., Vishwajith, 2017. Nano fertilizers is a new way to increase nutrients use efficiency in crop production. International Journal of Agriculture Sciences, 9(7): 3831-3833.

Solanki, P., Bhargava, A., Chhipa, H., Jain, N., Panwar, J., 2015. Nano-fertilizers and their smart delivery system. In: M. Rai, C. Ribeiro, L. Mattoso and N. Duran (Eds.), Nanotechnologies in Food and Agriculture. Springer.Sweitzerland, pp. 81-101.

Sönmez, İ., Kaplan, M., Sönmez, S., 2008. Kimyasal gübrelerin çevre kirliliği üzerine etkileri ve çözüm önerileri. Batı Akdeniz Tarımsal Araştırma Enstitüsü Derim Dergisi, 25(2): 24-34.

Valizadeh, M., Milic, V., 2016. The effects of balanced nutrient managements and nano-fertilizers effects on crop production in semi-arid areas. Current Opinion in Agriculture, 5(1): 31-38. 